\title{
Criptógamos do Parque Estadual das Fontes do Ipiranga, São Paulo, SP, Brasil. Pteridophyta: 7. Dryopteridaceae e 11. Lomariopsidaceae
}

\author{
Regina Yoshie Hirai ${ }^{1,2}$ e Jefferson Prado ${ }^{1}$
}

Recebido: 18.07.2012; aceito: 6.11.2012

\begin{abstract}
Cryptogams of Parque Estadual das Fontes do Ipiranga, São Paulo, São Paulo State, Brazil. Pteridophyta: 7. Dryopteridaceae and 11. Lomariopsidaceae). The data of the floristic survey of the families Dryopteridaceae and Lomariopsidaceae in Parque Estadual das Fontes do Ipiranga (PEFI) are presented. Five genera and nine species were found in the area. Dryopteridaceae is represented by two genera (Polybotrya and Rumohra) and four species: Polybotrya cylindrica Kaulf., P. semipinnata Fée, P. speciosa Schott, and Rumohra adiantiformis (G. Forst.) Ching, while Lomariopsidaceae is represented by three genera (Elaphoglossum, Mickelia, and Lomariopsis) and five species: Elaphoglossum ornatum (Mett. ex Kuhn) Christ, E. nigrescens (Hook.) T. Moore ex Diels, E. macrophyllum (Mett. ex Kuhn) Christ, Mickelia scandens (Raddi) R.C. Moran et al., and Lomariopsis marginata (Schrad.) Kuhn. Identification keys for genera and species, as well as descriptions, geographical distribution, comments, and illustrations for some studied taxa are presented.
\end{abstract}

Key words: Elaphoglossum, Lomariopsis, Mickelia, Polybotrya, Rumohra

RESUMO - (Criptógamos do Parque Estadual das Fontes do Ipiranga, São Paulo, SP, Brasil. Pteridophyta: 7. Dryopteridaceae e 11. Lomariopsidaceae). Neste trabalho são apresentados os dados referentes ao levantamento florístico das famílias Dryopteridaceae e Lomariopsidaceae no Parque Estadual das Fontes do Ipiranga (PEFI). No total foram encontrados na área cinco gêneros e nove espécies, sendo que Dryopteridaceae está representada por dois gêneros (Polybotrya e Rumohra) e quatro espécies: Polybotrya cylindrica Kaulf., P. semipinnata Fée, P. speciosa Schott e Rumohra adiantiformis (G. Forst.) Ching, enquanto Lomariopsidaceae está representada por três gêneros (Elaphoglossum, Mickelia e Lomariopsis) e cinco espécies: Elaphoglossum ornatum (Mett. ex Kuhn) Christ, E. nigrescens (Hook.) T. Moore ex Diels, E. macrophyllum (Mett. ex Kuhn) Christ, Mickelia scandens (Raddi) R.C. Moran et al. e Lomariopsis marginata (Schrad.) Kuhn. São apresentadas chaves para identificação dos gêneros e espécies, bem como descrições, distribuição geográfica, comentários e ilustrações para alguns dos táxons estudados.

Palavras-chave: Elaphoglossum, Lomariopsis, Mickelia, Polybotrya, Rumohra

\section{Introdução}

O presente estudo é parte do levantamento florístico das samambaias e licófitas do Parque Estadual das Fontes do Ipiranga (PEFI), que foi iniciado por Hoehne et al. (1941). Até o momento foram publicados os tratamentos para 19 das 24 famílias encontradas na área do Parque (Prado 2004a, b, c, d, e, f, g, 2006a, b, Prado \& Hirai 2008, 2010a, b, Prado et al. 2010 e Hirai \& Prado 2011).

Em relação aos trabalhos mais relevantes que tratam da taxonomia dos gêneros e espécies estudados na área do PEFI, destacam-se as monografias de: Polybotrya (Moran 1987), Lomariopsis (Moran 2000) e do grupo de Elaphoglossum ciliatum (Vasco et al. 2009), bem como a sinopse de Mickelia, gênero recentemente descrito (Moran et al. 2010a).

Além dessas revisões taxonômicas, existem algumas floras regionais para o Estado de São Paulo, nas quais podem ser encontradas algumas das espécies aqui estudadas. Dentre elas, pode ser citado Boldrin \& Prado (2007), que estudaram a flora de samambaias e licófitas para a área do Forte dos Andradas, Guarujá. Recentemente, também foi publicado um checklist

1. Instituto de Botânica, Núcleo de Pesquisa Curadoria do Herbário, Caixa Postal 68041, 04045-972 São Paulo, SP, Brasil

2. Autor para correspondência: regina.hirai@gmail.com 
para o Estado de São Paulo, baseado, em parte, na Lista da Flora do Brasil (Prado \& Sylvestre 2010), no qual são relacionadas todas as espécies desses grupos que ocorrem no Estado (Prado \& Hirai 2011). Além desse abrangente checklist, existem outros publicados anteriormente para algumas regiões pontuais, também envolvendo áreas na faixa leste do Estado, como por exemplo: Salino \& Almeida (2008), para o Parque Estadual de Jacupiranga e Prado \& Labiak (2009), para a Reserva Biológica do Alto da Serra de Paranapiacaba.

No trabalho realizado por Hoehne et al. (1941) foram citadas apenas duas espécies das famílias aqui estudadas na área do PEFI: Elaphoglossum decoratum (Kunze) T. Moore, cujo material foi trazido da Serra de Paranapiacaba para cultivo no Jardim Botânico e Polybotrya osmundacea Humb. \& Bonpl. ex Willd., essa nativa na área ( $=$ P. cylindrica Kaulf.).

O objetivo principal do presente trabalho é a complementação e atualização do levantamento das Dryopteridaceae e Lomariopsidaceae na área do PEFI.

\section{Material e métodos}

O material foi coletado de acordo com as técnicas descritas em Fidalgo \& Bononi (1984) e encontra-se depositado no Herbário do Instituto de Botânica (SP) e no Herbário do Departamento de Botânica da Universidade de São Paulo (SPF). Algumas duplicatas antigas encontram-se depositadas nos Herbários do Jardim Botânico de Nova York (NY), da Universidade de Harvard (GH) e no Instituto Smithsoniano (US), todos localizados nos Estados Unidos.

Os dados sobre a caracterização e localização do Parque Estadual das Fontes do Ipiranga (PEFI), bem como o planejamento dessa flora, foram apresentados em Melhem et al. (1981) e Milanez et al. (1990).

Neste trabalho seguiu-se as mesmas circunscrições de famílias utilizada por Moran \& Riba (1995) para a Flora Mesoamericana, de maneira idêntica à adotada desde o início das publicações da flora de samambaias do PEFI (Prado 2004a). Optou-se por apresentar essas duas famílias em um mesmo artigo, porque de acordo com a classificação mais recente de Smith et al. (2006, 2008), baseada em dados moleculares, Elaphoglossum atualmente está incluído em Dryopteridaceae.

O número que antecede o nome de cada família, no título deste trabalho, corresponde à numeração das famílias apresentadas em Prado (2004a). A chave para as famílias, incluindo Dryopteridaceae e Lomariopsidaceae, também foi publicada por Prado (2004a).
A abreviatura dos nomes dos autores de táxons está de acordo com Pichi-Sermolli (1996).

Optou-se por ilustrar apenas as espécies de Elaphoglossum, porque dentre todas as espécies aqui estudadas, são as que apresentam maior dificuldade para identificação. Os outros táxons são comuns nas floras regionais ou já foram tratados em monografias abrangentes e também encontram-se bem ilustradas.

Material adicional foi utilizado para complementação das descrições, nos casos em que determinadas estruturas não estavam presentes no material coletado no PEFI.

\section{Resultados e Discussão}

\section{Dryopteridaceae}

Plantas terrestres, rupícolas ou raramente hemiepífitas; rizoma ou caule ereto, curto a longo-reptante, ou longo-escandente, densamente revestido por escamas, estelo radial, com meristelos de tamanhos aproximados, arredondados em corte transversal. Frondes monomorfas ou dimorfas, contínuas com o rizoma, não articuladas; pecíolo com mais de 3 feixes vasculares na base, com escamas principalmente na base; pinas contínuas com a raque, não articuladas; raque, costa e cóstula sulcadas adaxialmente, os sulcos decorrentes entre si, pilosas ou glabras. Soros arredondados, oblongos, lineares ou acrosticóides; indúsio presente ou ausente; ânulo vertical, interrompido pelo pedicelo, pedicelo do esporângio com 3 fileiras de células na base da cápsula; paráfises presentes ou ausentes; esporos aclorofilados, monoletes.

Segundo Moran (1995a), a família apresenta 16 gêneros e cerca de 425 espécies. Na recente classificação de samambaias (Smith et al. 2006, 2008), vários gêneros foram agregados à família (por exemplo, Ctenitis e Elaphoglossum, anteriormente pertencentes a Tectariaceae e Lomariopsidaceae, respectivamente). Consequentemente, na atual circunscrição, a família apresenta 40-45 gêneros e 1.700 espécies, das quais $70 \%$ pertencem a quatro gêneros: Ctenitis, Dryopteris, Elaphoglossum e Polystichum.

Chave para os gêneros de Dryopteridaceae

1. Plantas hemiepífitas; frondes dimorfas; indúsio ausente; soros com paráfises ..... Polybotrya

1. Plantas exclusivamente terrestres; frondes monomorfas; indúsio presente; soros sem paráfises Rumohra 
Polybotrya Humb. \& Bonpl. ex Willd.

Plantas hemiepífitas. Caule longo-escandente, com escamas lanceoladas a linear-lanceoladas, amareladas, avermelhadas a castanhas, basifixas, margens inteiras a erodidas. Frondes dimorfas, as férteis com tecido laminar fortemente reduzido; pecíolo com escamas na base semelhantes às do caule; lâmina oblonga a lanceolada, 1-4-pinada, cartácea, tecido laminar glabro, ápice pinatífido a pinatissecto, margens inteiras ou ciliadas; raque densamente pilosa, com tricomas aciculares, unicelulares; pinas pecioluladas, pinas anadrômicas ou catadrômicas, pina apical raramente semelhante às laterais; nervuras livres ou anastomosadas. Soros acrosticóides, com esporângios revestindo totalmente os segmentos; paráfises presentes; indúsio ausente; esporos equinados.

Polybotrya apresenta 35 espécies, distribuídas da região Neotropical, sendo que o centro de diversidade do gênero é nos Andes, onde ocorrem 23 espécies, das quais 12 são endêmicas (Moran 1987). No Brasil ocorrem 13 espécies, sendo seis endêmicas (Moran 1987, Prado \& Sylvestre 2010).

Chave para as espécies de Polybotrya

1. Escamas do caule com margens inteiras, base espessada e recurvada; lâmina estéril 3-pinado-pinatissecta na região mediana P. cylindrica

1. Escamas do caule com margens subinteiras a erodidas, base membranácea, truncada e reta; lâmina estéril 2-pinado-pinatífida na região mediana

2. Escamas do caule castanho-escuras; lâmina estéril 2-pinado-pinatífida na base; soros com paráfises multicelulares e não ramificadas P. semipinnata

2. Escamas do caule castanho-avermelhadas; lâmina estéril 3-pinado-pinatífida na base, soros com paráfises multicelulares e ramificadas P. speciosa

Polybotrya cylindrica Kaulf., Enum. Filic.: 56. 1824.

Plantas com caule de 0,6-1,3 cm diâm.; escamas 8-10 × 1,0-1,2 mm, linear-lanceoladas, castanho-escuras, quase negras, base espessada e recurvada, margens inteiras, ápice acuminado a filiforme. Frondes estéreis com pecíolo de 46,5-54,0 cm compr.; lâmina estéril 43-99 × 45-60 cm, lanceolada, 3-pinado-pinatissecta a 3-pinado-pinatífida na base e na região mediana, glabra, margens geralmente ciliadas, ápice acuminado e pinatissecto; raque, raquíola e costa cobertas por tricomas e escamas adaxialmente e abaxialmente, tricomas 0,1-0,3 mm compr., alvos, às vezes levemente castanho-avermelhados, as escamas lineares, esparsas, castanho-escuras, margens inteiras, basifixas, e as escamas filiformes inconspícuas, castanho-avermelhadas, adpressas; pinas proximais 23-31 × 10,5-13,0 cm, pinas medianas catadrômicas; nervuras livres, simples ou furcadas. Fronde fértil com pecíolo de $46 \mathrm{~cm}$ compr., lâmina fértil $50 \times 31 \mathrm{~cm}$, lanceolada, 3-pinada na base, pinas 18-21 × 11-12 cm. Soros com paráfises pluricelulares, filiformes, simples, castanhas.

Material examinado: 20-IX-1973, O. Handro 2228 (GH, SP, US); trilha à direita da portaria 2, junto ao muro do Zoológico, 6-X-2003, J. Prado \& G.B. Silva 1428 (SP); trilha que margeia o Zoológico, 20-XII-2005, J. Prado \& G.B. Silva 1613 (SP).

Distribuição geográfica: Brasil - Pernambuco, Bahia, Alagoas, Espírito Santo, Rio de Janeiro, São Paulo, Paraná, Santa Catarina e Rio Grande do Sul.

É uma espécie endêmica da faixa leste do Brasil, onde se encontra a Mata Atlântica. Pode ser facilmente reconhecida pelas escamas do caule com a base curva e espessada. De acordo com Moran (1987), no Brasil esta é a espécie de Polybotrya que apresenta a lâmina mais vezes dividida (até 3-pinado-pinatífida), além de apresentar margens da lâmina esparsamente ciliadas. No entanto, o material Prado \& Silva 1428 difere um pouco dos outros espécimes da área do Parque por apresentar lâmina estéril com margens sem cílios e tricomas menores $(0,10-0,15 \mathrm{~mm}$ compr.) na raque, raquíola e costa. Apesar dessa variação morfológica, este espécime concorda com as demais características utilizadas por Moran (1987) no reconhecimento da espécie.

Ao contrário das demais espécies do gênero no PEFI, Polybotrya cylindrica é bastante comum e pode ser encontrada ao longo de toda a área do Parque, nas margens das trilhas.

Polybotrya semipinnata Fée, Crypt. Vasc. Brésil 1: 16.1869.

Plantas com caule de 1,1-1,3 cm diâm.; escamas 6,0-9,0 × 0,5-1,4 mm, lanceoladas, castanho-escuras a castanho-claras, base truncada, membranácea, margens denticuladas a levemente erodidas, ápice acuminado a filiforme, muitas vezes retorcido. 
Frondes estéreis com pecíolo de 22,0-27,5 cm compr.; lâmina estéril 17-36 × 20-24 cm, oblonga a lanceolada, 2-pinado-pinatífida na base e na região mediana, glabra, margens inteiras, ápice acuminado, pinatífido; raque e costa cobertos por tricomas e escamas adaxialmente e abaxialmente, tricomas 0,10-0,15 mm compr., alvos a levemente castanho-avermelhados, as escamas lanceolado-lineares, castanho-escuras a castanho-claras, esparsas, margens denticuladas, basifixas, e as escamas filiformes, inconspícuas, castanho-avermelhadas, adpressas; pinas proximais $11,5-12,5 \times 4,0-6,5 \mathrm{~cm}$, pinas medianas anadrômicas; nervuras livres, simples ou furcadas, levemente esbranquiçadas abaxialmente. Fronde fértil com pecíolo ca. 14,5 cm compr., lâmina fértil 24,0 $\times 14,5 \mathrm{~cm}$, oblongo-lanceolada, 3-pinada na base, pinas 12-15 ×6,0-7,0 cm. Soros com paráfises pluricelulares, filiformes, simples, castanhas.

Material examinado: s.d., O. Handro s.n. (SPF106928).

Material adicional examinado: São PaUlo, Peruíbe, Guaraú, 27-X-1891, A. Loefgren s.n. (SP21551).

Distribuição geográfica: Brasil - Bahia, Rio de Janeiro, São Paulo e Santa Catarina.

Também é uma espécie endêmica da Mata Atlântica e foi encontrada apenas uma única vez na área do PEFI. A espécie mais semelhante que também ocorre na área é Polybotrya speciosa, que difere por apresentar a lâmina mais dividida (3-pinado-pinatífida vs. 2-pinado-pinatífida na base), bem como pelo ápice da lâmina (pinatissecto vs. pinatífido). Além disso, $P$. semipinnata apresenta escamas do caule conspicuamente castanho-escuras a castanho-claras (vs. castanho-avermelhadas em $P$. speciosa).

Polybotrya speciosa Schott, Gen. Fil.: t. 7. 1834.

Plantas com caule de 2,0-2,5 cm diâm.; escamas 9,0-10,0 × 0,8-0,9 mm, linear-lanceoladas, castanho-avermelhadas, base truncada, membranácea, margens erodidas, ápice acuminado a filiforme. Frondes estéreis com pecíolo ca. 33,0 cm compr.; lâmina estéril $95,5 \times 50,0 \mathrm{~cm}$, lanceolada, 3-pinado-pinatífida na base, 2-pinado-pinatífida na região mediana, glabra, margens ciliadas, ápice acuminado e pinatissecto; raque, raquíola e costa cobertas por tricomas e escamas adaxialmente e abaxialmente, tricomas 0,3-0,5 mm compr., alvos a levemente castanho-avermelhados, as escamas linear-lanceoladas, esparsas, castanho-avermelhadas, margens denticuladas, basifixas, e as escamas filiformes, inconspícuas, castanho-avermelhadas, adpressas; pinas proximais $30 \times 17 \mathrm{~cm}$, pinas medianas anadrômicas; nervuras livres, simples ou furcadas. Fronde fértil com pecíolo de $17,5 \mathrm{~cm}$ compr., lâmina fértil 48,5 $\times 25,0 \mathrm{~cm}$, lanceolada, 3-pinada na base, pinas $10,5-14,0 \times 5,0-6,0 \mathrm{~cm}$. Soros com paráfises pluricelulares, filiformes, ramificadas, castanhas.

Material examinado: 28-I-1932, F.C. Hoehne s.n. (NY884613, SP28765).

Distribuição geográfica: Brasil - Bahia, Minas Gerais, Espírito Santo, Rio de Janeiro e São Paulo.

Também é uma espécie endêmica da Mata Atlântica. Pode ser reconhecida pelas escamas do caule castanho-avermelhadas com margens fortemente denticuladas e também pelas paráfises multicelulares e ramificadas.

\section{Rumohra Raddi}

Plantas terrestres. Rizoma longo-reptante, com escamas ovais a lanceoladas, peltadas, margens inteiras a denteadas. Frondes monomorfas, dispostas em duas fileiras dorsais no caule; pecíolo com escamas a glabrescente; lâmina deltóide a oblongo-deltóide, 2-3-pinado-pinatífida a pinatissecta, coriácea, tecido laminar glabro ou com tricomas glandulares, ápice acuminado, margens inteiras; pinas pecioluladas, anadrômicas; raque com escamas a glabrescente, as escamas lanceoladas ou filiformes; nervuras livres, simples ou furcadas. Soros arredondados; indúsio presente, peltado; esporos geralmente tuberculados.

Rumohra éum gênero pequeno de Dryopteridaceae, com cerca de 6 espécies, sendo que estas apresentam uma distribuição Circum-Antártica (Smith 1995). Segundo Condack (2010), ocorrem apenas duas espécies no Brasil, sendo uma delas endêmica e com distribuição restrita ao Estado do Rio Grande do Sul (Rumohra turficola R.M. Senna).

Rumohra adiantiformis (G. Forst.) Ching, Sinensia 5: 70. $1934 \equiv$ Polypodium adiantiforme G. Forst., Fl. Ins. Austr.: 82. 1786.

Plantas com rizoma de 0,8-1,0 cm diâm.; escamas 8,0-9,0 $\times 4,0-6,0 \mathrm{~mm}$, oval-lanceoladas, castanho-claras, margens inteiras a levemente denteadas, ápice agudo a acuminado. Frondes com pecíolo de 36-54 cm compr.; pecíolo e raque esparsamente cobertos por escamas adaxialmente e abaxialmente, as escamas lanceoladas, 4,0-6,0 $\times 0,4-0,5 \mathrm{~mm}$, castanho-claras a castanho-escuras, margens inteiras a erodidas, ápice longo-acuminado, e as escamas aracnóides, 1,0-1,5 × 0,1-0,3 mm, castanho-claras; lâmina 38,5-49,5 × 25-40 cm, oval, 3-pinado-pinatífida 
a 3-pinado-crenada na base, glabra; pinas proximais 20,5-29,0 × 11,5-18,0 cm, ovais, pecioluladas, margens inteiras, ápice acuminado, pinatissecto; nervuras livres, bifurcadas. Soros com indúsio castanho-escuro, margem inteira.

Material examinado: 18-XII-1951, O. Handro 286 (SP); barranco atrás do Museu Botânico, na área de visitação, 20-X-2003, J. Prado \& D.M. Vital 1448 (SP); 2340'18"S, 46³8'00"W, 700 m.s.m., 10-II-2009, J. Prado \& R.Y. Hirai 2022 (SP).

Distribuição geográfica: África, Austrália, Madagascar, Nova Zelândia, Bermudas, Grandes Antilhas, América do Sul, incluindo Brasil - Acre, Pernambuco, Ceará, Bahia, Distrito Federal, Mato Grosso do Sul, Minas Gerais, Espírito Santo, Rio de Janeiro, São Paulo, Paraná, Santa Catarina e Rio Grande do Sul.

Rumohra adiantiformis é uma espécie bastante comum ao longo de toda a Mata Atlântica. É facilmente reconhecida, uma vez que é a única espécie de Rumohra que ocorre na área do Parque. A divisão da lâmina (3-pinado na base) e a presença de soros com indúsio peltado são bastante características do gênero.

\section{Lomariopsidaceae}

Plantas terrestres, hemiepífitas ou epífitas. Rizoma ou caule reptante ou, raramente, ereto (Elaphoglossum), coberto densamente por escamas, estelo dorsiventral, o meristelo ventral oblongo ou linear, com vários meristelos dorsais circulares ou quase circulares em corte transversal. Frondes dimorfas, articuladas ou contínuas com o rizoma ou caule, filopódios presentes ou ausentes; pecíolo com 3 feixes vasculares na base, com escamas principalmente na base, às vezes as escamas densamente dispostas ao longo do pecíolo; pinas articuladas ou contínuas com a raque; raque e costa arredondadas ou sulcadas, com escamas, raramente pilosas ou glabras. Soros acrosticóides; indúsio ausente; ânulo vertical, interrompido pelo pedicelo, pedicelo do esporângio com 2 ou 3 fileiras de células na base da cápsula; paráfises ausentes; esporos aclorofilados, monoletes.

Segundo Moran (1995b), a família apresenta sete gêneros e 600 espécies. É reconhecida por apresentar soros acrosticóides e um grande meristelo ventral facilmente observado em corte transversal do rizoma. Na classificação de Smith et al. (2006), Lomariopsidaceae apresenta quatro gêneros (Cyclopeltis, Lomariopsis, Nephrolepis e Thysanosoria), com cerca de 70 espécies.
Chave para os gêneros de Lomariopsidaceae

1. Frondes inteiras; pecíolo articulado com o caule; filópodio presente Elaphoglossum

1. Frondes 1-pinadas, pinas inteiras; pecíolo contínuo com o caule; filopódio ausente

2. Nervuras anastomosadas, sem vênulas inclusas ... Mickelia

2. Nervuras livres Lomariopsis

Elaphoglossum Schott ex J. Sm.

Plantas epífitas ou rupícolas. Caule curto a longo-reptante, raramente ereto, com ou sem escamas, quando presentes, alaranjadas a negras, base geralmente cordada a subcordada, margens inteiras a denteadas. Frondes fasciculadas ou espaçadas entre si, eretas ou pendentes; pecíolo articulado com o caule, sulcado adaxialmente, base com filopódio negro, nas porções mediana e distal esverdeado ou paleáceo, com escamas ou glabro, às vezes com tricomas glandulares; lâmina inteira, linear, oblanceolada, elíptica, coriácea, cartácea ou carnosa, glabra ou com escamas de diferentes formas, costa sulcada adaxialmente, geralmente com escamas semelhantes às do pecíolo abaxialmente; lâmina fértil recoberta por esporângios na face abaxial, geralmente menor e mais estreita que a estéril; nervuras livres às vezes conectando-se lateralmente, simples a 2-furcadas.

Elaphoglossum é um grupo grande com cerca de 600 espécies distribuídas amplamente no mundo, sendo que $3 / 4$ delas ocorrem no Neotrópico (Mickel \& Smith 2004). Ao contrário de outras espécies de samambaias epífitas na área do PEFI, essas plantas não foram reencontradas recentemente, talvez porque sejam mais susceptíveis à poluição atmosférica bastante intensa nessa área.

\section{Chave para as espécies de Elaphoglossum}

1. Pecíolo e margens da lâmina estéril densamente revestidos por escamas ovallanceoladas E. ornatum

1. Pecíolo esparsamente revestido por escamas ou glabro; margens da lâmina estéril glabras ou com escamas estreladas esparsas

2. Margens da lâmina glabras; caule com escamas; lâmina sem pontos resinosos abaxialmente; pecíolo da fronde fértil castanho-claro E. macrophyllum

2. Margens da lâmina com algumas escamas estreladas; caule desprovido de escamas; lâmina com pontos resinosos abaxialmente; pecíolo da fronde fértil negro E. nigrescens 
Elaphoglossum macrophyllum (Mett. ex Kuhn) Christ, Bull. Herb. Boissier, sér. 2, 5(1): 10. $1905 \equiv$ Acrostichum macrophyllum Mett. ex Kuhn, Linnaea 36: 61. 1869.

Figuras 1A-D

Plantas epífitas. Caule curto-reptante, $1,0-2,0 \mathrm{~cm}$ compr., com escamas de 1,1-1,3 × 0,2-0,3 mm, oval-lanceoladas, castanho-escuras, margens fimbriadas, ápice acuminado. Frondes férteis com pecíolos castanho-claros, 16-17 cm compr. (vs. 7,5-13 cm compr. nas frondes estéreis); pecíolo com escamas esparsas, semelhantes às do caule e escamas estreladas, reduzidas, ca. 0,5 mm compr., conspícuas, castanho-escuras a negras; lâmina estéril 37,0-46,5 × 6,0-7,7 cm, oblongo-lanceolada, coriácea, base atenuada, margens inteiras, ápice agudo; lâmina fértil 26-29,5 × 4,5-4,7 cm, oblongo-lanceolada, base atenuada, margens inteiras, ápice agudo a acuminado; escamas da lâmina abaxialmente e adaxialmente estreladas, semelhantes às do pecíolo; nervuras geralmente livres, furcadas, algumas anastomosadas. Material examinado: 18-I-1971, O. Handro 2157 (SP, SPF).

Distribuição geográfica: Venezuela, Guiana, Guiana Francesa e Brasil - Ceará, Bahia, Distrito Federal, Minas Gerais, Espírito Santo, Rio de Janeiro, São Paulo, Paraná, Santa Catarina e Rio Grande do Sul.

Elaphoglossum macropyllum é uma espécie conhecida pelo seu porte grande. É a espécie do gênero que apresenta a maior lâmina foliar estéril que ocorre na área do Parque, com 37,0-46,5 cm compr. (vs. 19-24 cm compr. e 35-36 cm compr. em E. nigrescens e E. ornatum, respectivamente). Pode ser facilmente distinta das outras espécies pelas características utilizadas na chave, mas também pela base da lâmina (atenuada vs. decorrente e cuneada em E. nigrescens e E. ornatum, respectivamente). Segundo alguns autores (por exemplo, Alston 1958), Elaphoglossum macrophyllum caracteriza-se por apresentar geralmente nervuras anastomosadas próximo da margem da lâmina. Esta última característica é facilmente observada nas plantas que ocorrem no PEFI.

Elaphoglossum nigrescens (Hook.) T. Moore ex Diels, Nat. Pflanzenfam. 1(4): $332.1899 \equiv$ Acrostichum nigrescens Hook., Sp. Fil. 5: 214. 1864.

Figuras 1E-G

Plantas epífitas. Caule longo-reptante, 2,0-2,5 cm diâm., glabro. Frondes férteis com pecíolo negro, proporcionalmente maior que nas frondes férteis, ca. $26 \mathrm{~cm}$ compr. (vs. 6,0-15,5 cm compr.); pecíolo sem escamas, alado distalmente; lâmina estéril 19-24 × 1,3-2,0 cm, lanceolada, coriácea, base decorrente, margens inteiras, ápice agudo; lâmina fértil 15,0 $\times 0,8 \mathrm{~cm}$, linear, base decorrente, margens inteiras, ápice agudo; escamas esparsas nas margens da lâmina, reduzidas, ca. $1 \mathrm{~mm}$ compr., estreladas, no tecido laminar ausentes, e pontos resinosos mais conspícuos abaxialmente; nervuras livres, simples a furcadas.

Material examinado: 12-III-1955, O. Handro 456 (SP).

Distribuição geográfica: Nicarágua, Costa Rica, Panamá, Colômbia, Venezuela, Guiana, Equador, Peru, Bolívia e Brasil - Amazonas, Ceará, Bahia, Minas Gerais, Espírito Santo, Rio de Janeiro, São Paulo, Paraná e Santa Catarina.

Esta espécie distingue-se das outras espécies de Elaphoglossum que ocorrem no Parque pela presença de pontos resinosos sobre a lâmina, facilmente visíveis abaxialmente, e também por apresentar o pecíolo da lâmina fértil negro, característica que deu nome a espécie.

Elaphoglossum ornatum (Mett. ex Kuhn) Christ, Neue Denkschr. Allg. Schweiz. Ges. Gesammten Naturwiss. 36:38.1899 $\equiv$ Acrostichum ornatum Mett. ex Kuhn, Linnaea 36: 44. 1869.

Figuras $1 \mathrm{H}-\mathrm{K}$

Plantas epífitas. Caule curto-reptante, com escamas de 4,0-5,0 $\times$ 0,5-1,0 mm, oval-lanceoladas, castanho-claras, margens denticuladas. Frondes férteis com pecíolo castanho-claro, proporcionalmente maior nas frondes férteis, ca. $15 \mathrm{~cm}$ compr. (vs. $11-13,5 \mathrm{~cm}$ ); pecíolo densamente revestido por escamas 5,0-6,0 × 0,4-0,7 mm compr., linear-lanceoladas, castanho-claras, margens denticuladas, às vezes com alguns cílios na base; lâmina estéril 35-36 × 2,6-4,7 cm, oblongo-lanceolada, subcoriácea, base cuneada, algumas vezes levemente cordada, costa e margens com escamas, ápice arredondado; lâmina fértil $12,0 \times 0,5-0,6 \mathrm{~cm}$, linear, base atenuada, margens inteiras, ápice acuminado; escamas da margem da lâmina, oval-lanceoladas, ca. 2,5 mm compr., castanho-claras, margens denticuladas, contíguas e adpressas ao tecido laminar, raramente escamas estreladas reduzidas no tecido laminar abaxialmente, ca. 0,3 $\mathrm{mm}$, inconspícuas, castanho-escuras a negras; nervuras geralmente livres, furcadas, raramente anastomosadas. 


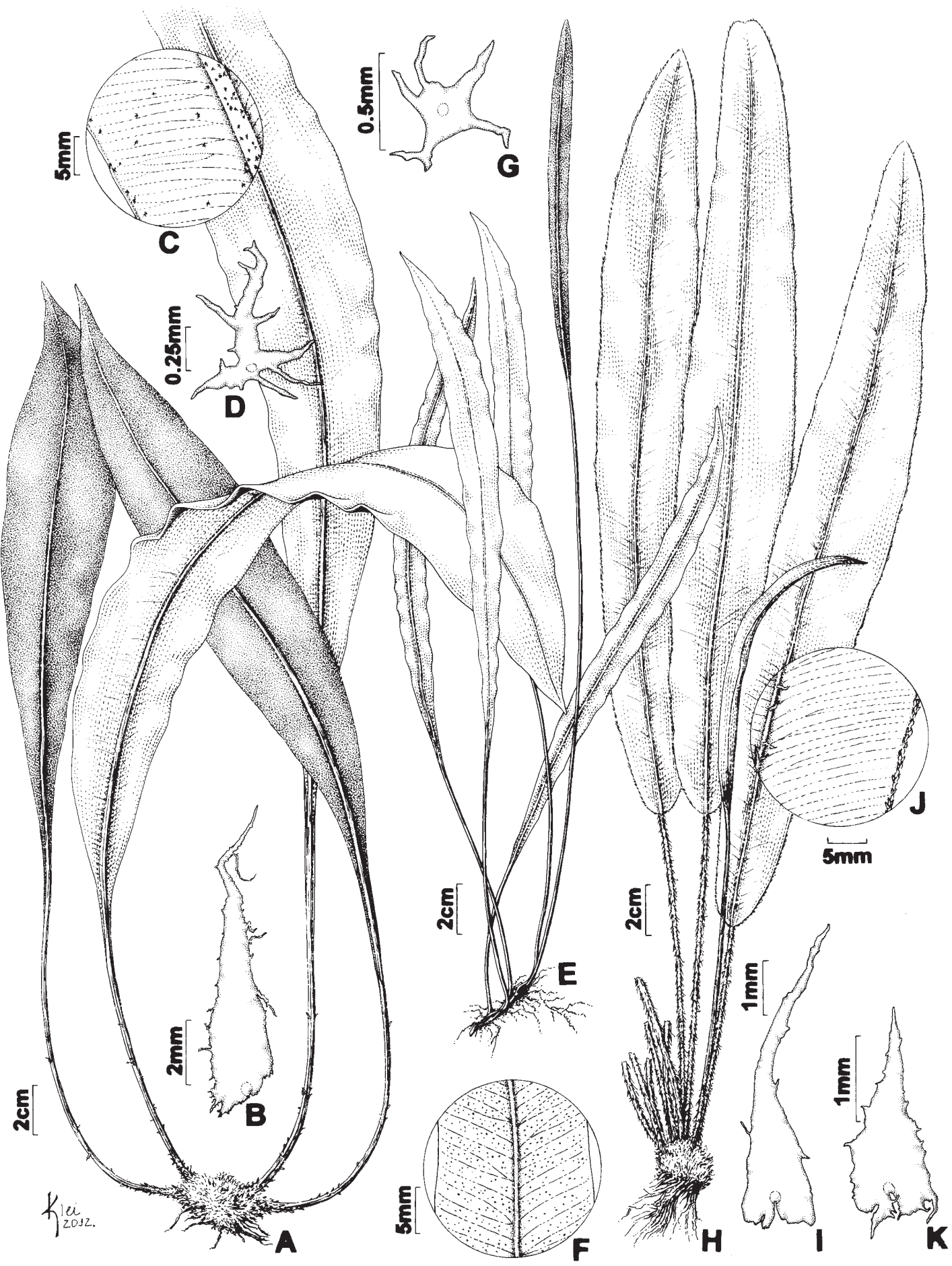

Figura 1. A-D. Elaphoglossum macrophyllum (Handro 2157). A. Hábito. B. Escama do pecíolo. C. Lâmina abaxialmente mostrando nervuras e escamas estreladas. D. Escama estrelada da lâmina. E-G. E. nigrescens (Handro 456). E. Hábito. F. Lâmina abaxialmente mostrando nervuras e pontos resinosos. G. Escama da margem da lâmina. H-K . E. ornatum (Eiten et al. 2082). H. Hábito. I. Escama do pecíolo. J. Lâmina abaxialmente mostrando nervuras e escamas sobre a costa e margem da lâmina. K. Escama da margem da lâmina.

Figure 1. A-D. Elaphoglossum macrophyllum (Handro 2157). A. Habit. B. Scale from the petiole. C. Abaxial view of lamina, showing veins and stellate scales. D. Stellate scale from lamina. E-G. E. nigrescens (Handro 456). E. Habit. F. Abaxial view of lamina, showing veins and resinous dots. G. Scale from lamina margin. H-K. E. ornatum (Eiten et al. 2082). H. Habit. I. Scale from the petiole. J. Abaxial view of lamina, showing veins and scales on the costa and lamina margin. K. Scale from lamina margin. 
Material examinado: 13-VII-1960, G. Eiten et al. 2082 (SP).

Distribuição geográfica: Venezuela, Bolívia e Brasil Rio de Janeiro, São Paulo, Paraná, Santa Catarina e Rio Grande do Sul.

Elaphoglossum ornatum é distinta das outras espécies que ocorrem na área pela presença de escamas por todo o pecíolo, bem como nas margens da lâmina. Essas escamas chamam bastante a atenção na planta pela sua localização, especialmente aquelas dispostas nas margens da lâmina.

\section{Lomariopsis Fée}

Plantas hemiepífitas. Caule longo-escandente, filopódio ausente, escamas peltadas, com margens ciliadas a denteadas. Frondes espaçadas entre si, eretas ou pendentes; pecíolo contínuo com o caule, sulcado adaxialmente, glabro ou com escamas na base; lâmina 1-pinada, cartácea a subcoriácea, glabra; lâmina fértil recoberta por esporângios na face abaxial, geralmente mais estreita que a estéril, disposta no ápice do caule escandente; pinas articuladas com a raque, pina apical semelhante às pinas laterais (pina conforme); nervuras livres, às vezes conectando-se lateralmente.

É um gênero com distribuição Pantropical, com cerca de 45 espécies, das quais 15 ocorrem no Neotrópico (Moran 2000). No Brasil ocorrem quatro espécies, uma das quais endêmica da Mata Atlântica, ocorrendo na área do PEFI.

Lomariopsis marginata (Schrad.) Kuhn, Reis Ost-Afr. Bot. 3(3): 22. 1879 ELomaria marginata Schrad., Gel. Anz. 1824: 871. 1824.

Caule 0,7-1,2 cm diâm.; escamas 8,0-10,0× 1,0-1,2 mm, lanceoladas, castanho-claras a castanho-avermelhadas, às vezes negras no centro, margens ciliadas. Frondes estéreis com pecíolos de 11,5-23,5 cm compr.; lâmina $31-80 \times 13-26 \mathrm{~cm}$, levemente reduzida na base, pinas 6,8-20,0 $\times 1,4-2,8 \mathrm{~cm}$, sésseis ou subsésseis, patentes, lanceoladas, base cuneada, margens levemente serreadas, ápice acuminado; raque não alada, com escamas semelhantes às do caule e também escamas subestreladas, filiformes. Fronde fértil com pecíolo de $11-12 \mathrm{~cm}$ compr., lâmina $40-42 \times 14,0-15,0 \mathrm{~cm}$, pinas $7,5-12,0 \times 0,4-0,5 \mathrm{~cm}$.

Material examinado: 7-XI-1965, R. Faria 12 (SP); 23-XII-1971, O. Handro 2192 (SPF); 23-IV-1979, A. Tosta Silva 304 (SP); 6-X-2003, J. Prado \& D.M. Vital 1432 (SP); trilha próxima ao Zoológico, 700 m.s.m., 26-V-2009, J. Prado \& R. Y. Hirai 2023 (NY, SP).
Distribuição geográfica: Endêmica do Brasil - Bahia, Minas Gerais, Espírito Santo, Rio de Janeiro, São Paulo, Paraná e Santa Catarina.

A espécie mais semelhante a Lomariopsis marginata, e que também ocorre na área do PEFI, é Mickelia scandens por apresentar frondes pinadas, com pinas articuladas à raque. No entanto, elas diferem principalmente pelo padrão de nervuras (nervuras livres vs. nervuras areoladas, respectivamente). Segundo Moran (2000), L. marginata é distinta de outras espécies de Lomariopsis por apresentar escamas do caule castanho-avermelhadas e pela presença de maior número de pares de pinas (geralmente 10-20 vs. menos que 10 pinas nas outras espécies).

\section{Mickelia R.C. Moran et al.}

Plantas hemiepífitas, raramente terrestres. Caule ou rizoma curto a longo-reptante, filopódio ausente; escamas subpeltadas, margens ciliadas. Frondes espaçadas entre si, eretas ou pendentes; pecíolo contínuo com o caule ou, raramente, articulado, sulcado adaxialmente; lâmina 1-pinada ou, raramente, 2-pinada; gemas ausentes ou presentes nas axilas das pinas; pinas articuladas ou contínuas com a raque, inteiras ou distalmente serreadas, pina apical semelhante às pinas laterais (pina conforme); nervuras anastomosadas, com ou sem vênulas inclusas, às vezes livres nas margens da lâmina.

Mickelia é um gênero que foi recentemente segregado de Bolbitis Schott, mais especificamente do grupo de "Bolbitis nicotianifolia". É um gênero totalmente Neotropical, com dez espécies (Moran et al. 2010a, b).

$\mathrm{Na}$ área do PEFI ocorre uma única espécie deste gênero: Mickelia scandens.

Mickelia scandens (Raddi) R.C. Moran et al., Brittonia 62(4): 354, f. 1i, 4f-j. $2010 \equiv$ Acrostichum scandens Raddi, Syn. Fil. Bras.: 6, t. 34. 1819.

Plantas hemiepífitas. Caule 0,5-0,8 cm diâm.; escamas 4,0-6,5 × 0,2-0,5 mm, linear-lanceoladas, castanho-claras a castanho-escuras, margens inteiras, às vezes com alguns cílios. Frondes estéreis com pecíolos de 9,0-21,0 cm compr.; lâmina 25-46 × 9-22 cm, levemente reduzida na base; com gemas nas axilas das pinas; pinas articuladas, 6-11,5 × 1,3-1,7 cm, 13-27 pares, patentes, curtamente pecioladas, lanceoladas, base cuneada, margens serreadas, ápice acuminado; raque não alada, sulcada adaxialmente, com escamas semelhantes às do caule, margens 
levemente denticuladas; nervuras areoladas, sem vênulas inclusas, geralmente 2 séries de aréolas entre a costa e a margem, com nervuras livres próximas, mas não atingindo as margens. Fronde fértil com pecíolo de 7,0-9,0 cm compr., lâmina 27-29 ×6,0-6,5 cm, pinas $2,5-3,3 \times 0,2-0,3 \mathrm{~cm}$, com escamas semelhantes às da lâmina estéril, mas com margens ciliadas.

Material examinado: 23-XI-1972, O. Handro 2214 (SPF); trilha que margeia o Zoológico, 20-XII-2005, J. Prado \& G.B. Silva 1610 (SP); trilha próximo ao Zoológico, 2340'18"S, 46³8'00"W, 700 m.s.m., 26-V-2009, J. Prado \& R.Y. Hirai 2025 (NY, SP); idem, 21-VIII-2009, J. Prado \& P.B. Schwartsburd 2032 (SP).

Distribuição geográfica: Endêmica do Brasil - Rio de Janeiro, São Paulo, Paraná, Santa Catarina e Rio Grande do Sul.

Mickelia scandens foi encontrada na área do Parque em locais sombreados, como epífita sobre fanerógamas. É uma espécie facilmente reconhecida pela presença de nervuras areoladas, sem vênulas inclusas, pecíolo articulado com o caule e o ápice da lâmina reduzido. Antes da criação do gênero Mickelia, esta espécie do leste do Brasil foi por longo tempo tratada como Polypodium guianense Aubl., Leptochilus guianensis (Aubl.) C. Chr. ou Lomagramma guianensis (Aubl.) Ching. Entretanto, de acordo com o trabalho de Moran et al. (2010b), este táxon foi primeiramente descrito por Raddi (1819) como Acrostichum scandens.

\section{Agradecimentos}

Ao CNPq, pela concessão da Bolsa de Produtividade em Pesquisa ao segundo Autor e auxílio para este projeto (processo 300843-93-3). O segundo Autor também agradece a Daniel M. Vital e a Giovanna B. da Silva, pela ajuda no trabalho de campo.

\section{Literatura citada}

Alston, A.H.G. 1958. The Brazilian species of Elaphoglossum. Boletim da Sociedade Broteriana 32: 1-32.

Boldrin, A.H.L. \& Prado, J. 2007. Pteridófitas terrestres e rupícolas do Forte dos Andradas, Guarujá, São Paulo, Brasil. Boletim de Botânica da Universidade de São Paulo 25: 1-69.
Condack, J.P.S. 2010. Rumohra. In: J. Prado \& L.S. Sylvestre (coords.). Samambaias e licófitas. In: R.C. Forzza, J.F. Baumgratz, C.E. M. Bicudo, D. Canhos, A.A. Carvalho Jr., A. Costa, D.P. Costa, M. Hopkins, M.P. Leitman, L.G. Lohmann, E.N. Lughadha, L.C. Maia, G. Martinelli, M. Menezes, M.P. Morin, M. Nadruz, A.L. Peixoto, J.R. Pirani, J. Prado, L.P. Queiroz, S. Souza, V.C. Souza, J.R. Stehmann, L.S. Sylvestre, B.M.T. Walter \& D.C. Zappi (eds.). Catálogo de Plantas e Fungos do Brasil. 1 ed. Jardim Botânico do Rio de Janeiro, Rio de Janeiro, v.1, pp. 537.

Fidalgo, O. \& Bononi, V.L.R. (coords.). 1984. Técnicas de coleta, preservação e herborização de material botânico. Manual 4. Instituto de Botânica, São Paulo.

Hirai, R.Y. \& Prado, J. 2011. Criptógamos do Parque Estadual das Fontes do Ipiranga, São Paulo, SP. Pteridophyta: 10. Hymenophyllaceae. Hoehnea 38: 501-510.

Hoehne, F.C., Kuhlmann, M. \& Handro, O. 1941. O Jardim Botânico de São Paulo. Secretaria da Agricultura, Indústria e Comércio, Departamento de Botânica do Estado, São Paulo.

Melhem, T.S., Giulietti, A.M., Forero, E., Barroso, G.M., Silvestre, M.S.F., Jung, S.L., Makino, H., Melo, M.M.R.F., Chiea, S.C., Wanderley, M.G.L., Kirizawa, M. \& Muniz, C. 1981. Planejamento para elaboração da "Flora Fanerogâmica da Reserva do Parque Estadual das Fontes do Ipiranga (São Paulo, Brasil)". Hoehnea 9: 63-74.

Mickel, J.T. \& Smith, A.R. 2004. The Pteridophytes of Mexico. Mexico. Memoirs of the New York Botanical Garden 88: 1-1055.

Milanez, A.I., Bicudo, C.E.M., Vital, D.M. \& Grandi, R.A.P. 1990. Criptógamos do Parque Estadual das Fontes do Ipiranga, São Paulo, SP: Planejamento. Hoehnea 17: 43-49.

Moran, R.C. 1987. Monograph of the Neotropical fern genus Polybotrya (Dryopteridaceae). Illinois Natural History Survey Bulletin 34: 1-138.

Moran, R.C. 1995a. Dryopteridaceae. In: R.C. Moran \& R. Riba (eds.). Psilotaceae a Salviniaceae. In: G. Davidse, M.S. Sousa \& S. Knapp (eds.). Flora Mesoamericana, v.1. Universidad Nacional Autónoma de México, Ciudad de México, pp. 210-226.

Moran, R.C. 1995b. Lomariopsidaceae. In: R.C. Moran \& R. Riba (eds.). Psilotaceae a Salviniaceae. In: G. Davidse, M.S. Sousa \& S. Knapp (eds.). Flora Mesoamericana, v.1. Universidad Nacional Autónoma de México, Ciudad de México, pp. 247-285.

Moran, R.C. 2000. Monograph of the Neotropical species of Lomariopsis (Lomariopsidaceae). Brittonia 52: 55-111.

Moran, R.C. \& Riba, R. 1995. Psilotaceae a Salviniaceae. In: G. Davidse, M.S. Sousa \& S. Knapp (eds.), Flora Mesoamericana. Universidad Nacional Autónoma de México, Ciudad de México, v.1, pp. 1-470. 
Moran, R.C., Labiak, P.H. \& Sundue, M. 2010a. Synopsis of Mickelia, a newly recognised genus of bolbitidoid ferns (Dryopteridaceae). Brittonia 62: 337-356.

Moran, R.C., Labiak, P.H. \& Sundue, M. 2010 b. Phylogeny and character evolution of the bolbitidoid ferns (Dryopteridaceae). International Journal of Plant Sciences 171: 547-559.

Pichi-Sermolli, R.E.G. 1996. Authors of scientific names in Pteridophyta. Royal Botanic Gardens, Kew.

Prado, J. 2004a. Criptógamos do Parque Estadual das Fontes do Ipiranga, São Paulo, SP. Pteridophyta: chave para as famílias; 2. Blechnaceae. Hoehnea 31: 1-10.

Prado, J. 2004b. Criptógamos do Parque Estadual das Fontes do Ipiranga, São Paulo, SP. Pteridophyta: 6. Dicksoniaceae. Hoehnea 31: 239-242.

Prado, J. 2004c. Criptógamos do Parque Estadual das Fontes do Ipiranga, São Paulo, SP. Pteridophyta: 14. Ophioglossaceae. Hoehnea 31: 171-174.

Prado, J. 2004d. Criptógamos do Parque Estadual das Fontes do Ipiranga, São Paulo, SP. Pteridophyta: 17. Pteridaceae. Hoehnea 31: 39-49.

Prado, J. 2004e. Criptógamos do Parque Estadual das Fontes do Ipiranga, São Paulo, SP. Pteridophyta: 8. Gleicheniaceae. Hoehnea 31: 33-37.

Prado, J. 2004f. Criptógamos do Parque Estadual das Fontes do Ipiranga, São Paulo, SP. Pteridophyta: 5. Dennstaedtiaceae. Hoehnea 31: 11-22.

Prado, J. 2004g. Criptógamos do Parque Estadual das Fontes do Ipiranga, São Paulo, SP. Pteridophyta: 15. Osmundaceae. Hoehnea 31: 93-96.

Prado, J. 2006a. Criptógamos do Parque Estadual das Fontes do Ipiranga, São Paulo, SP. Pteridophyta: 18. Salviniaceae. Hoehnea 33: 107-110.

Prado, J. 2006b. Criptógamos do Parque Estadual das Fontes do Ipiranga, São Paulo, SP. Pteridophyta: 12. Lophosoriaceae. Hoehnea 33: 123-126.

Prado, J. \& Hirai, R.Y. 2008. Criptógamos do Parque Estadual das Fontes do Ipiranga, São Paulo, SP. Pteridophyta: 13. Lycopodiaceae e 20. Selaginellaceae. Hoehnea 35: 543-552.

Prado, J. \& Hirai, R.Y. 2010a. Criptógamos do Parque Estadual das Fontes do Ipiranga, São Paulo, SP. Pteridophyta: 21. Tectariaceae. Hoehnea 37: 367-376.

Prado, J. \& Hirai, R.Y. 2010b. Criptógamos do Parque Estadual das Fontes do Ipiranga, São Paulo, SP. Pteridophyta: 4. Davalliaceae, 19. Schizaeaceae, 23. Vittariaceae e 24. Woodsiaceae. Hoehnea 37: 791-800.
Prado, J. \& Hirai, R.Y. 2011. Checklist das licófitas e samambaias do Estado de São Paulo, Brasil. Biota Neotropica 11: 161-190.

Prado, J. \& Labiak, P.H. 2009. Pteridófitas. In: M.I.M.S. Lopes, M. Kirizawa \& M.M.R.F. Melo (orgs.). Patrimônio da Reserva Biológica do Alto da Serra de Paranapiacaba: a antiga Estação Biológica do Alto da Serra. Instituto de Botânica, São Paulo, pp. 269-289.

Prado, J. \& Sylvestre, L.S. 2010. Samambaias e licófitas. In: R.C. Forzza, J.F. Baumgratz, C.E. M. Bicudo, D. Canhos, A.A. Carvalho Jr., A. Costa, D.P. Costa, M. Hopkins, M.P. Leitman, L.G. Lohmann, E.N. Lughadha, L.C. Maia, G. Martinelli, M. Menezes, M.P. Morin, M. Nadruz, A.L. Peixoto, J.R. Pirani, J. Prado, L.P. Queiroz, S. Souza, V.C. Souza, J.R. Stehmann, L.S. Sylvestre, B.M.T. Walter \& D.C. Zappi (eds.). Catálogo de Plantas e Fungos do Brasil. 1 ed. Jardim Botânico do Rio de Janeiro, Rio de Janeiro, v.1, pp. 522-567.

Prado, J., Hirai, R.Y. \& Schwartsburd, P.B. 2010. Criptógamos do Parque Estadual das Fontes do Ipiranga, São Paulo, SP. Pteridophyta: 9. Grammitidaceae e 16. Polypodiaceae. Hoehnea 37: 445-460.

Raddi, J. 1819. Synopsis filicum brasiliensium auctore Josepho Raddio ex XLviris Societatis Italicae Scientiarum aliarumque Academiarum Socio, Bononiae.

Salino, A. \& Almeida, T.E. 2008. Pteridófitas do Parque Estadual de Jacupiranga, SP, Brasil. Acta Botanica Brasilica 22: 983-991.

Smith, A.R. 1995. Pteridophytes. In: J.A. Steyermark, P.E. Berry \& B.K. Holst (eds.). Pteridophytes and Spermatophytes (Acanthaceae to Araceae). v.2.In: P.E. Berry, B.K. Holst \& K. Yatskievych (coords.). Flora of the Venezuelan Guayana. Timber Press, Portland, pp. 1-334.

Smith, A.R., Pryer, K.M., Schuettpelz, E., Korall, P., Schneider, H. \& Wolf, P.G. 2006. A classification for extant ferns. Taxon 55: 705-731.

Smith, A.R., Pryer, K.M., Schuettpelz, E., Korall, P., Schneider, H. \& Wolf, P.G. 2008. Fern classification. In: T.A. Ranker \& C.H. Haufler (eds.). Biology and evolution of ferns and lycophytes. Cambridge University Press, Cambridge, pp. 417-467.

Vasco, A., Moran, R.C. \& Rouhan, G. 2009. Monograph of the Elaphoglossum ciliatum group (Dryopteridaceae). Brittonia 61: 241-272. 